\title{
Eco-Friendly Building Energy Consumption Analysis based on Interpretive Structure Model
}

\author{
Abdulraheem I. T. ${ }^{1}$ and Liu Kaiyu ${ }^{2}$ \\ ${ }^{1}$ University of Ilorin, P.M.B. 1515, Ilorin, Nigeria \\ ${ }^{2}$ Shanghai Urban Construction Vocational College, China \\ abdulraheem_it@unilorin.edu.ng
}

\begin{abstract}
Based on the Interpretive Structure Model (ISM) method, this paper studies six factors that affect the energy consumption of Eco-friendly buildings, and analyzes the relationship between several factors by establishing a matrix. The research results show that environmental factors have the greatest impact on building energy consumption, followed by energy-saving policies and human behavior.
\end{abstract}

Keywords: Interpretive structure model, Energy consumption, Eco-friendly building

\section{Introduction}

As one of the three major industries in social development, the construction industry has had a huge impact on human production and life. In order to cope with the global energy and resource shortage problem and alleviate the deterioration of the ecological environment, the construction industry has born a new type of environmentally friendly building that fits the concept of sustainable development-Eco-friendly building.

In recent years, the energy-saving effect of Eco-friendly buildings has been controversial [1]. Therefore, researchers have conducted in-depth research on the energy-saving mechanism and influencing factors of Eco-friendly buildings. Lin Borong and others have studied the envelope structure, HVAC system, domestic hot water system and renewable energy system of Eco-friendly buildings, and believe that natural ventilation and lighting technology have good energy-saving effects, and human behavior patterns have a greater impact on energy consumption [2]. Wu Xuejun studied and proposed that the new HVAC technology can effectively adjust the energy consumption of buildings and the surrounding environment to provide people with a more comfortable living space [3]. Ji Ran et al. studied and analyzed the energy-saving characteristics of building envelopes from three aspects: exterior walls, exterior windows and roofing, and provided references for energy-saving design of buildings [4]. Peng Bo et al. used DeST software to simulate the heating energy consumption of the building during operation [5]. Through the selection of windows and the optimization of the window-to-wall ratio, the heating energy consumption during operation decreased by approximately $21.4 \%$. He Yueer and others quantified the energy-saving benefits of Ecofriendly buildings from the two aspects of envelope structure and energy technology, and believed that the reasonable setting of external sunshade and the change of thermal performance of the envelope structure can produce an energy saving rate of 7\% [6]. Esin T

Article history:

Received (March 10, 2020), Review Result (April 15, 2020), Accepted (May 19, 2020) 
studied the energy consumption of building materials from the perspective of the entire life cycle of the building. The results show that saving the use of building materials and increasing material utilization can reduce building energy consumption [7]. Baniassadi a et al. calculated and analyzed the impact of high albedo roof on energy consumption of residential buildings with roof as the research object [8].

This paper comprehensively and comprehensively summarizes the factors influencing the energy consumption of Eco-friendly buildings, and selects several factors that have a greater impact as research parameters to analyze the influence of various factors on building energy consumption based on ISM method. And put forward corresponding energy-saving countermeasures.

\section{Selection of influencing factors of Eco-friendly building energy consumption}

In this paper, through reviewing a large number of relevant documents, we have sorted out many factors that affect the energy consumption of Eco-friendly buildings. After research and analysis, we have selected the six most important factors, which are building shape and orientation, window shading and window-to-wall ratio, building enyelope Structure, human behavior, environmental factors, energy-saving policies.

\subsection{Building envelope Structure}

The building envelope is the most important module that affects building energy consumption, with walls having the greatest impact on building energy consumption. The energy-saving design of the wall is directly related to the energy consumption of the building. The key to energy-saving of the wall is insulation. The exterior wall of the building serves as an insulation layer for indoor and outdoor air, and its insulation form and effect are particularly important. There are three types of exterior wall insulation: exterior wall exterior insulation, exterior wall interior insulation and exterior wall sandwich insulation. Among them, exterior wall exterior insulation is the most widely used and has the greatest impact on building energy consumption. Tests by relevant institutions have shown that if the building wall is not insulated, its energy consumption accounts for about 50\% of the energy consumption of the entire building structure. If insulation treatment is performed, it will drop to $10 \% \sim 15 \%$. It can be seen that the thermal insulation performance of the building envelope structure is related to the energy-saving effect of the entire building.

\subsection{Building shape and orientation}

The shape of the building directly determines the shape factor of the building. The shape factor refers to the ratio of the area of the building exposed to the air to the building volume. The larger the shape factor, the larger the heat dissipation area of the building, and the greater the energy consumption of the building with the same heat transfer coefficient. The orientation of the building directly affects the natural ventilation and lighting of the building. In the same area, the sun height angle is the same, and the light intensity received by the building in different directions is different. In our country, north-south-facing buildings are more energy-efficient than east-west-facing buildings.

\subsection{Window shading and window-to-wall ratio}


As far as the building itself is concerned, the window is an important factor affecting building energy consumption due to its poor airtightness and large heat transfer coefficient, and is a weak link in building insulation, heat insulation, and sound insulation. In summer, the intensity of solar radiation is large, and direct sunlight will cause overheating in the building interior, resulting in increased energy consumption in the building.

Window shading can prevent most of the sunlight from being irradiated directly, part of the sunlight is reflected back to the air by the glass, and the other part is absorbed by the door and window materials, thereby reducing the room temperature, improving the indoor thermal environment, reducing the use of air conditioning, and achieving energy saving and emission reduction. The heat transfer coefficient of a window is greater than that of an external wall with the same orientation and the same area. The larger the heat transfer coefficient, the worse the thermal insulation function. Therefore, building energy consumption also increases with the increase of the window-to-wall ratio.

\subsection{Human behavior}

The function of architecture is to serve people's production and life. At the same time, human behavior will also have an effect on architecture. In addition to normal walking movements, human behaviors have an important impact on building energy consumption. For example, indoor movements, opening windows, turning on lights, air conditioning, and shading directly affect building energy consumption. The heating and cooling of a building is mainly controlled by human behavior. The lifestyles and work schedules will affect the length of building lighting, the setting of air conditioning temperature, and the length of air conditioning. These behavioral preferences basically determine the electricity consumption during the building operation phase and affect building energy consumption.

\subsection{Energy-saving policies}

Building energy conservation policy guidelines will play a leading role in the construction market and indicate the path and direction for the development of the construction industry. The relevant policies issued by the government can play a positive role in building energy efficiency. Personal behavior awareness and enterprise production standards are affected by the policy. Wu Qi et al. used measurement methods such as dummy variables and cointegration test to qualitatively study and objectively analyze the impact of energy-saving policies and energy-saving intensity of buildings in China. The study found that energysaving policies for buildings have an important impact in saving resources and reducing energy consumption, its impact is second only to energy-saving technology.

\subsection{Environmental factors}

The local microclimate at the location of the building has an important impact on building energy consumption. In summer, the outdoor temperature is relatively high. In order to meet the needs of human comfort, cooling devices such as air conditioners are usually needed. When the outdoor temperature is low in winter, the indoor temperature needs to be increased with the help of heating equipment. The higher the temperature (lower), the more power is consumed by the cooling (heating) equipment. In addition, the outdoor Eco-friendly rate also has an impact on the local microclimate of the building. Green plants absorb cO2 through photosynthesis, which can reduce the surrounding air temperature to a certain extent. Improving outdoor microclimate, reducing building energy consumption and improving 
indoor environmental quality has become an important direction in the field of urban planning and architectural design.

\section{ISM model}

Interpretive Structure Modeling (ISM) is a system structure modeling technology. It decomposes a complex system into several subsystems, uses practical experience and computer assistance, and finally constitutes a multi-layer hierarchical structural model. It needs to list the adjacency matrix through the influence of factors, and operate on the basis of the known adjacency matrix to obtain the reachability matrix, and then decompose the reachability matrix to obtain the stepped structure. Explaining the structural model can directly find out the direct and indirect risk factors, and find the key points to solve the problem.

First, number the six influencing factors of Eco-friendly building energy consumption selected above, as shown in [Table 1].

Table 1. Key influence factors in energy consumption of Eco-friendly buildings

\begin{tabular}{|c|c|c|}
\hline No. & Influence Factor & Ei \\
\hline 1 & Building Envelope Structure & E1 \\
\hline 2 & Building Shape And Orientation & E2 \\
\hline 3 & Window Shading And Window-To-Wall Ratio & E3 \\
\hline 4 & Human Behavior & E4 \\
\hline 5 & Energy-Saving Policies & E5 \\
\hline 6 & Environmental Factors & E6 \\
\hline
\end{tabular}

\subsection{Determine the logical relationship between various influencing factors}

Establish ISM discussion group, composed of 15 members, including 6 researchers engaged in construction and 9 experts in construction industry. They used the brainstorming method for group discussion. After the discussion, the logical relationship between the six influencing factors was determined, as shown in [Table 2].

Table 2. Matrix table of logical relationship of influencing factors of Eco-friendly building energy consumption

\begin{tabular}{|c|c|c|c|c|c|c|}
\hline & $\begin{array}{c}\text { Building } \\
\text { envelope } \\
\text { Structure } \\
\text { E1 }\end{array}$ & $\begin{array}{c}\text { Window } \\
\text { shading and } \\
\text { window-to- } \\
\text { wall ratio } \\
\text { E2 }\end{array}$ & $\begin{array}{c}\text { Building } \\
\text { shape and } \\
\text { orientation } \\
\text { E3 }\end{array}$ & $\begin{array}{c}\text { Human } \\
\text { behavior E4 }\end{array}$ & $\begin{array}{c}\text { Energy- } \\
\text { saving } \\
\text { policies E5 }\end{array}$ & $\begin{array}{c}\text { Environmental } \\
\text { factors E6 }\end{array}$ \\
\hline $\begin{array}{c}\text { Building } \\
\text { envelope } \\
\text { Structure E1 }\end{array}$ & - & 1 & 0 & 0 & 0 & 0 \\
\hline $\begin{array}{c}\text { Window shading } \\
\text { and window-to- } \\
\text { wall ratio E2 }\end{array}$ & 1 & - & 1 & 0 & 0 & 0 \\
\hline
\end{tabular}




\begin{tabular}{|c|c|c|c|c|c|c|}
\hline $\begin{array}{c}\text { Building shape } \\
\text { and orientation } \\
\text { E3 }\end{array}$ & 0 & 0 & - & 0 & 0 & 0 \\
\hline $\begin{array}{c}\text { Human behavior } \\
\text { E4 }\end{array}$ & 1 & 1 & 1 & - & 1 & 0 \\
\hline $\begin{array}{c}\text { Energy-saving } \\
\text { policies E5 }\end{array}$ & 0 & 0 & 0 & 1 & - & 0 \\
\hline $\begin{array}{c}\text { Environmental } \\
\text { factors E6 }\end{array}$ & 1 & 1 & 1 & 1 & 1 & - \\
\hline
\end{tabular}

In [Table 2], the values 0 and 1 indicate the correlation between $E_{i}$ and $E_{j}$. If $E_{j}$ has an effect on $E_{i}$, it's recorded as 1 . If $E_{j}$ has no effect on $E_{i}$, it's recorded as 0 . When the two factors affect each other, the larger one will be considered.

\subsection{Establish ISM adjacency matrix and generate ISM reachable matrix}

The adjacency matrix A represents the direct relationship between various factors. There is no need to describe the direct relationship between the same factors, so their correlation is 1 , that is, the diagonal of the matrix is 1, and then establish ISM adjacency matrix A based on the logical relationship matrix table [Table 2].

$$
A=\left|\begin{array}{llllll}
1 & 1 & 0 & 0 & 0 & 0 \\
1 & 1 & 1 & 0 & 0 & 0 \\
0 & 0 & 1 & 0 & 0 & 0 \\
1 & 1 & 1 & 1 & 1 & 0 \\
0 & 0 & 0 & 1 & 1 & 0 \\
1 & 1 & 1 & 1 & 1 & 1
\end{array}\right|
$$

The reachability matrix $\mathrm{M}$ is mainly used to describe the indirect relationship between various factors.

According to the Boolean matrix algorithm, sum the adjacency matrix $\mathrm{A}$ and the identity matrix I, and the power of $\mathrm{A}+\mathrm{I}$ to obtain the reachable matrix $\mathrm{M}$, should meet the formula:

$$
M=(A+I)^{n+1}=(A+I)^{n} \neq(A+I)^{n-1}
$$

Then calculate M:

$$
M=\left|\begin{array}{llllll}
1 & 1 & 0 & 0 & 0 & 0 \\
1 & 1 & 1 & 0 & 0 & 0 \\
0 & 0 & 1 & 0 & 0 & 0 \\
1 & 1 & 1 & 1 & 1 & 0 \\
1 & 1 & 1 & 1 & 1 & 0 \\
1 & 1 & 1 & 1 & 1 & 1
\end{array}\right|
$$

\subsection{Divide the layer of influencing factors}

First, first select the factors affected by the element $E_{i}$, and create a set to count these elements. We call this set the reachable set $S\left(E_{i}\right)$. We also need to create a set of elements that affect the element $E_{i}$, this set is named the prior set $A\left(E_{i}\right)$. Then, the set created is only for the element $E_{i}$. After the statistics of the elements, as long as $S\left(E_{i}\right) \cap A\left(E_{i}\right)=S\left(E_{i}\right)$, then Ei is the first-layer element of the model. 
Finally, all the first-layer elements can be obtained by the above method, all rows and columns of the upper-layer factor reachable matrix are deleted, and the remaining elements are iterated to finally obtain all the lowest-layer elements of the system.

Therefore, the top-layer factor, that is, the termination layer factor is $S(F)=E_{3}$. Remove this factor, the remaining five factors establish the adjacency matrix and calculate the reachability matrix according to the above steps, and find the new reachable set and the prior set and common set. Repeat the above steps until all factors are layered. To summarize and analyze the logical relationship between the influencing factors in the reachable matrix $M$, it can be divided into reachable set $R\left(E_{i}\right)$, prior set $A\left(E_{i}\right)$ and common set $C\left(E_{i}\right)$, as shown in [Table 3].

Table 3. Reachable set, prior set and common set

\begin{tabular}{|c|c|c|c|}
\hline$E_{i}$ & $R\left(E_{i}\right)$ & $A\left(E_{i}\right)$ & $C\left(E_{i}\right)$ \\
\hline 1 & $1,2,3$ & $1,2,4,5,6$ & 1,2 \\
\hline 2 & $1,2,3$ & $1,2,4,5,6$ & 1,2 \\
\hline 3 & 3 & $1,2,3,4,5,6$ & 3 \\
\hline 4 & $1,2,3,4,5$ & $4,5,6$ & 4,5 \\
\hline 5 & $1,2,3,4,5$ & $4,5,6$ & 4,5 \\
\hline 6 & $1,2,3,4,5,6$ & 6 & 6 \\
\hline
\end{tabular}

\subsection{Build IEM Model}

According to the above calculation results, the first-layer factor set is $\{\mathrm{E} 3\}$, after removing $\{\mathrm{E} 3\}$, the second-layer factor set is calculated as $\{\mathrm{E} 1, \mathrm{E} 2\}$. Then remove $\{\mathrm{E} 1, \mathrm{E} 2, \mathrm{E} 3\}$, and the third-layer factor set is calculated as $\{E 4, E 5\}$. Similarly, the fourth-layer factor set is $\{$ E6\}. As the number of layers increases, this factor has a greater impact on the energy consumption of Eco-friendly buildings. The factors between the layers are connected with arrows, and the factors between the layers do not need to establish a connection, thus building an ISM model, as shown in [Figure 1].

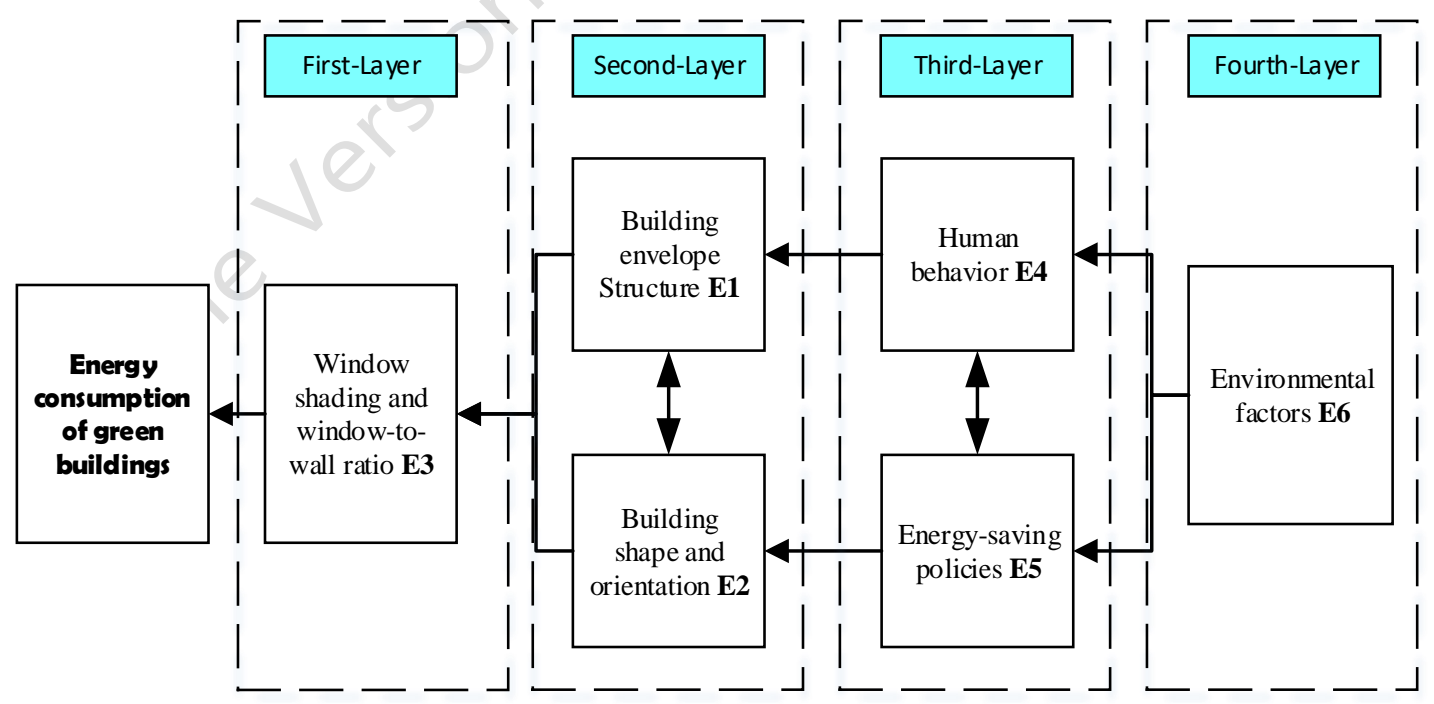

Figure 1. ISM model for influence factors of Eco-friendly building energy consumption 


\section{Result analysis}

The model is a four-layers Eco-friendly building energy consumption influencing factor explanatory structural model, which shows the direction of the influence between the factors from bottom to top.

The absence of arrows between compartment factors does not mean that they are unrelated, and there may be an indirect relationship.

(1) The first layer of influencing factors are window insulation and shading, which are the most direct and basic factors that affect the energy consumption of Eco-friendly buildings.

(2) The influencing factors of the second layer also affect the influencing factors of the first layer. The orientation and shape of the building affect the number and area of windows. The size of the building envelope will affect the shape of the building. In addition, the shape of the building will limit the building envelope which in turn affects Eco-friendly building energy consumption.

(3) The third layer of factors is the building energy conservation policy and human behavior.

The direction of building energy-saving policies directly affects the decision-making behavior of developers (or owners) to adopt energy-saving technologies. Human factors will also be promoted by energy-saving policies, which will enable them to raise energy-saving awareness and adopt energy-saving measures.

(4) The climatic factor of the fourth layer is the root cause of the increase in energy consumption of Eco-friendly buildings. The climate directly affects the external temperature of the building. Global warming increases the external temperature of the building. Through heat conduction, the indoor temperature also rises, resulting in increased energy consumption for air conditioning. The warming of the climate has aroused people's attention and affected people's behavior. At the same time, it has received special attention from the government and relevant departments, and accordingly adopted energy-saving policies.

\section{Conclusion}

Based on the ISM method, the paper studies six factors that affect the energy consumption of Eco-friendly buildings, and analyzes the relationship between several factors by establishing a matrix. The research results show that environmental factors have the greatest impact on building energy consumption, followed by energy-saving policies and human behavior. According to the mutual influence between various factors and the degree of impact on building energy consumption, the following suggestions are proposed.

(1) Improving the ecological environment is urgent.

Although ecological governance and climate improvement is a long-term and slow process, it is a fundamental way to alleviate resource shortages and energy problems from a long-term perspective. In addition, improving local climate conditions, such as increasing the Ecofriendly area around the building, is also an effective way to reduce building energy consumption.

(2) Speed up the implementation of effective and applicable guidelines and policies

In my country, the government's role in leading and regulating the market is very important. The introduction of energy-saving policies has pointed out the direction for energy conservation and emission reduction in the construction industry, and it can also regulate the energy-saving behaviors of enterprises and individuals.

(3) Give play to the publicity and education of the media and schools 
Energy consumption during the operation and maintenance of Eco-friendly buildings mainly comes from lighting, cooling and heating. Therefore, human activities and behavioral preferences will play an important role in energy consumption, and energy conservation awareness is particularly important.

\section{Reference}

[1] Wang Mengjuan, Lin Xinyan, and Chen Jian, "Research on energy-saving measures of green buildings," Construction Science and Technology, vol.2019, no.24, pp.75-81, (2019) DOI: 10.16116/j.cnki.jskj.2019.24.015

[2] Lin Borong and Xiao Juan, "POE research on common energy saving technology applied to green buildings in China," Heating Ventilating and Air Conditioning, vol.2012, no.10, pp.20-25, (2012)

[3] Wu Xuejun, "Analysis on the application and influence of new HVAC technology in green building," Construction Materials and Decoration, vol.2020, no.3, (2020)

[4] Ji Ran, Sun Ruiyi, and Zhang Shu, "Analysis of energy saving effect of building envelope," Heilongjiang Science and Technology Information, vol.2016, no.7, (2016)

[5] Peng Bo and Lin Borong, "Optimization of green building material selection based on LCA: A residential case study in cold area," Eco-city and Green Building, vol.2014, no.4, (2014)

[6] He Yueer, Ding Yong, and Liu Meng, "Analysis of energy efficiency of green buildings in hot-summer and cold-winter zones in China," Journal of Civil, Architectural and Environmental Engineering, vol.2018, no.1, (2018)

[7] Esin T., "A study regarding the environmental impact analysis of the building materials production process (in Turkey)," Building and Environment, vol.42, no.11, pp.3860-3871, (2007)

[8] Baniassadi A, Sailor D J, Crank P J, et al., "Direct and indirect effects of high-albedo roofs on energy consumption and thermal comfort of residential buildings," Energy \& Buildings, vol.178, pp.71-83, (2018) 